\title{
Virulence patterns of Vibrio cholerae non-01 strains isolated from hospitalised patients with acute diarrhoea in Calcutta, India
}

\author{
T. RAMAMURTHY, PRASANTA K. BAG, AMIT PAL, S. K. BHATTACHARYA, \\ M. K. BHATTACHARYA, TOSHIO SHIMADA*, TAE TAKEDA $\dagger$, TADAHIRO KARASAWA \\ HISAO KURAZONO $\ddagger$ YOSHIFUMI TAKEDA $\ddagger$ and G. BALAKRISH NAIR $\S$ \\ National Institute of Cholera and Enteric Diseases, Beliaghata, Calcutta-700 010, India; * Department of \\ Bacteriology, National Institute of Health, Shinjuku-ku, Tokyo 162; $\uparrow$ Department of Infectious Diseases Research \\ National Children's Medical Research Center, Setagaya-ku, Tokyo 154; $\ddagger$ Department of Microbiology, Faculty of \\ Medicine, Kyoto University, Kyoto 606, Japan
}

\begin{abstract}
Summary. A collection of 28 strains of Vibrio cholerae non-O1 isolated during a 3-year period (1989-1991) from hospitalised patients with acute diarrhoea in Calcutta, India, were examined with regard to virulence-associated factors. Of the 28 isolates (each representing a case), 18 were isolated as the sole infecting agent; the remaining 10 were recovered as cocultures from cases infected with $V$. cholerae $\mathrm{O}$. Of the strains isolated in this study, $82 \%$ could be serotyped, with serovars O5 (32.1\%), O11 and O34 (14.3\% each) predominant. Serovars $\mathrm{O} 7, \mathrm{O} 14, \mathrm{O} 34, \mathrm{O} 39$ and $\mathrm{O} 97$ were associated exclusively with sole infections. Two strains of $V$. cholerae non-O1 produced anti-cholera toxin IgG-absorbable cholera toxin (CT). Both CT-producing $V$. cholerae non-O1 strains hybridised with the DNA probe specific for the zonula occludens toxin (ZOT) but none of the remaining 26 strains hybridised with the ZOT probe. The majority of the strains were cytotoxic for $\mathrm{CHO}, \mathrm{HeLa}$ and Vero cells, with end-point titres of 4-512. Fewer strains produced a cytotonic effect, with end-point titres of $2-16$. Of the 28 strains of $V$. cholerae non-O1 examined, $75 \%, 75 \%, 25 \%$ and $14.3 \%$ produced haemolysin that was active against erythrocytes of rabbit, sheep (Eltor haemolysin), chicken and man, respectively. Strains that produced a haemolysin active against both rabbit and sheep erythrocytes were dominant (35.7\%). Ten $(35.7 \%)$ of the 28 strains examined showed cell-associated haemagglutinating activity on human blood. Of the 10 strains, nine were isolated as sole pathogen and only one strain was associated with mixed infection. Three distinct patterns of inhibition by sugars were detected; inhibition of haemagglutination by mannose $1 \%$ but not by fucose and galactose $1 \%$ was the dominant haemagglutination inhibition pattern. Six different virulence phenotypes were encountered among strains of $V$. cholerae non-O1 in this study. The prominent phenotype, which was associated commonly with isolates from patients solely infected by $V$. cholerae non-O1, was exhibited by strains that produced the Eltor haemolysin, a cytotoxin and a cell-associated haemagglutinin. The production of cell-associated haemagglutinin appeared to be the only distinctive phenotype that could distinguish between isolates from patients solely infected with $V$. cholerae non-O1 and those associated with mixed infections. From this study, it is apparent that the virulence of $V$. cholerae non-O1 is multifactorial and mediated by several traits functioning in an integrated fashion. The clinical significance of $V$. cholerae non-O1 must be assessed in its totality; the presence of a single factor should not be construed as the cause of enteropathogenicity.
\end{abstract}

\section{Introduction}

Whereas the aetiological role of Vibrio cholerae non-O1 (previously referred to as the nonagglutinating vibrios or NAG vibrios) as the causative

Received 10 March 1993; revised version accepted 6 April 1993. $\S$ Correspondence should be sent to Dr G. Balakrish Nair. agent of gastroenteritis is unequivocal, the virulence factor(s) responsible for eliciting the disease is obscure. Apart from gastrointestinal infections, ${ }^{1} V$. cholerae non-O1 has occasionally been implicated in various infections in man including cellulitis, ${ }^{2}$ wound infections ${ }^{3}$ and septicaemia. ${ }^{4}$ This range of symptoms suggests a complex mechanism of pathogenesis and strains are likely to possess various virulence factors in 
different combinations. In recent years, several extracellular products have been documented as playing an important role in the disease process, including a heat-stable enterotoxin (NAG-ST) consisting of 17 amino acids, which bears close similarity to the heat-stable enterotoxins of enterotoxigenic Escherichia coli, ${ }^{5-8}$ a heat-labile enterotoxin related to cholera toxin, ${ }^{9-13}$ a heat-labile Eltor-like haemolysin ${ }^{14,15}$ that induces fluid accumulation in the infant mouse, ${ }^{16}$ a thermostable direct haemolysin similar to that of $V$. parahaemolyticus, ${ }^{6,17}$ a Shiga-like toxin $^{18}$ and haemagglutinins. ${ }^{19,20}$ However, attempts to correlate the production of the enterotoxin, cytotoxin, haemolysin and haemagglutinins with enteropathogenicity have not shown consistent results and no single virulence factor has been shown to predict whether a particular strain is pathogenic or not.

A recent volunteer study in man demonstrated that in the presence of adequate colonisation factor(s), a NAG-ST-producing strain of $V$. cholerae non-O1 caused diarrhoea of severity similar to that seen in cholera. ${ }^{21}$ However, the frequency of occurrence of NAG-ST among strains of $V$. cholerae non-O1 is low ${ }^{22}$ indicating that other, hitherto unknown enterotoxigenic factor(s) may be involved in the causation of acute secretory diarrhoea. This study was initiated to further our understanding of the virulence factor(s) associated with $V$. cholerae non-O1 strains isolated either as the sole infecting pathogen or as co-cultures in infections of polymicrobial aetiology from hospitalised patients with acute diarrhoea in Calcutta.

\section{Materials and methods}

\section{Specimens}

During the period July 1989-Nov. 1991, 591 patients hospitalised with acute diarrhoea and admitted to the Infectious Disease Hospital, Calcutta, were investigated. Stool specimens were collected immediately on admission, in sterile MacCartney bottles with sterile catheters. Soon after collection, stool specimens were transported to the laboratory and examined within $2 \mathrm{~h}$ for $V$. cholerae and for other common toxigenic enteropathogens such as enterotoxigenic E. coli (ETEC), Shigella, Salmonella and Campylobacter spp. by standard published techniques. ${ }^{23}$

\section{Isolation and phenotypic characterisation}

Plates of Thiosulphate-Citrate-Bile Salts-Sucrose Agar (TCBS; Eiken, Japan) were streaked with two or three loopfuls of stool specimens for selective isolation of $V$. cholerae. After incubation overnight at $37^{\circ} \mathrm{C}$, 10-15 typical colonies from each stool sample showing growth on the selective agar were inoculated on to a multi-test medium, ${ }^{24}$ which combines the principles of triple sugar-iron agar and Kligler's iron agar, to facilitate rapid presumptive identification of $V$. cholerae. In the multi-test medium, fermentation of glucose and inositol or rhamnose, arginine dehydrolation, indole production, $\mathrm{H}_{2} \mathrm{~S}$ production from sodium thiosulphate indicated by ferric ammonium citrate, and gas production can be recorded from a single tube. The rationale for examining 10-15 isolates/case was to explore whether $V$. cholerae non$\mathrm{O} 1$ occurred as co-cultures with $V$. cholerae $\mathrm{O} 1$ from patients with cholera and, if so, how frequently. Strains that showed typical alkaline slant-acid butt reaction on the multi-test medium were examined for the oxidase reaction and slide agglutination was performed with polyvalent $\mathrm{Ol}$ and monospecific Ogawa-Inaba antisera prepared at the National Institute of Cholera and Enteric Diseases, Calcutta, India. Strains that did not agglutinate with the $\mathrm{O} 1$ antisera were characterised biochemically with the API 20E system (Analytab products, Plainview, NY, USA). Antibiotic susceptibility testing was performed by the disk diffusion technique. ${ }^{23}$

\section{Serogrouping}

The identities of the $V$. cholerae that did not agglutinate with the $\mathrm{O} 1$ antisera were re-confirmed and the serovars of strains were determined by the somatic $O$ antigen serogrouping scheme $^{25}$ at the National Institute of Health, Tokyo, Japan.

\section{Bacterial preparations}

All the $V$. cholerae non-O1 strains were maintained in nutrient agar as stabs at room temperature until required. All media used in this study except TCBS were from Difco Laboratories, Michigan, USA. The broth media used for assessing production of cholera toxin-like enterotoxin was Casamino-Acid Yeast Extract (CAYE) medium supplemented with $90 \mu \mathrm{g} / \mathrm{ml}$ lincomycin (Sigma). ${ }^{10}$ Trypticase soy broth containing yeast extract $0.6 \%$ was used for the tissue culture and haemolysin assays. The test strains were cultivated in the above media at $37^{\circ} \mathrm{C}$ for $24 \mathrm{~h}$ in a rotatory shaker (Firstek Scientific, USA) set at c. $200 \mathrm{rpm}$. After centrifugation $\left(5000 \mathrm{rpm}\right.$ for $20 \mathrm{~min}$ at $\left.4^{\circ} \mathrm{C}\right)$, the culture supernate was filtered $(0 \cdot 2-\mu \mathrm{m}$ disposable filter; Sigma) and the cell-free culture filtrate was used for the various assays.

\section{Assay for cholera toxin-like enterotoxin and thermostable direct haemolysin by bead-ELISA}

All the culture filtrates of the $V$. cholerae non-O1 strains were examined for the presence of cholera toxin (CT)-like enterotoxin and for thermostable direct haemolysin in a highly sensitive bead-ELISA. ${ }^{26-28}$ Various dilutions of purified CT (Sigma) or the culture filtrate of strain NICED 10 of Kanagawa phenomenon-positive $V$. parahaemolyticus (positive 
controls) and uninoculated medium (negative control) were run concurrently whenever a batch of the culture filtrate of the test strains were assayed by the beadELISA.

\section{Absorption assay with anti-CT IgG}

An absorption assay by bead-ELISA was performed to determine whether CT present in culture supernates of strains yielding a positive result by the CT beadELISA could be absorbed with anti-CT IgG. In this assay, culture supernate of the CT-producing strain was pre-incubated at $37^{\circ} \mathrm{C}$ for $1 \mathrm{~h}$ with $10 \mu \mathrm{g}$ of rabbit anti-CT IgG $/ \mathrm{ml}$. From earlier experiments it was determined that $10 \mu \mathrm{g}$ of anti-CT $\mathrm{IgG} / \mathrm{ml}$ can completely absorb $500 \mathrm{ng}$ of pure $\mathrm{CT} / \mathrm{ml}$. Subsequently, the coated beads were introduced into $0.5 \mathrm{ml}$ of the above-described incubation and the bead-ELISA was performed as described previously. ${ }^{27}$

\section{Cytotoxin and cytotonic toxin assays}

$\mathrm{CHO}$ and HeLa cells were grown as monolayers in Dulbecco's Minimum Essential Medium (Nissui Pharmaceutical Co. Ltd, Japan) supplemented with horse serum (Gibco Laboratories, USA) $10 \% \mathrm{v} / \mathrm{v}$ and Vero cells were grown as monolayers in Minimum Essential Medium (Gibco Laboratories) supplemented with horse serum $10 \%$. Cultures were maintained in tissue-culture flasks $\left(25 \mathrm{~cm}^{2}\right)$ at $37^{\circ} \mathrm{C}$ in a humidified $\mathrm{CO}_{2} 5 \%$ atmosphere. Samples $(50 \mu \mathrm{l})$ of the culture filtrate of the test strains, serially diluted in Hanks's Balanced Salts Solution (Gibco Laboratories), were added to each well of 96-well tissue culture plates. A confluent monolayer of $\mathrm{CHO}$, HeLa or Vero cells grown for 3-4 days was removed from the tissue culture flasks and $200 \mu \mathrm{l}$ of the cell suspension (c. $4 \times 10^{3}$ cells) was added to each of the 96-well plates and incubated as described above. Cytotonic and cytotoxic changes were recorded at 24 and $48 \mathrm{~h}$. For controls, wells received the uninoculated culture medium (negative control) and pure cholera toxin or the culture filtrate of reference strains of $E$. coli $\mathrm{C} 984$ producing Shiga-like toxin I and E. coli B1409 producing Shiga-like toxin II as positive controls (by courtesy of Nancy A. Strockbine, Centers for Disease Control, Atlanta, GA, USA).

\section{Haemolysin assay}

Haemolytic activity of the $V$. cholerae non-O1 strains with erythrocytes from rabbit, sheep, chicken and man was determined as described previously. ${ }^{29}$ Briefly, washed erythrocytes were diluted to a final concentration of $1 \%$ in $10 \mathrm{~mm}$ phosphate-buffered saline (PBS; $\mathrm{pH} 7.0$ ) containing $\mathrm{NaCl} 1.3 \%$ and mixed 1 to 1 with the culture filtrate of the test strains. The mixture was centrifuged at $1000 \mathrm{rpm}$ for $5 \mathrm{~min}$. The amount of released haemoglobin in the supernate was measured spectrophotometrically at $540 \mathrm{~nm}$. An optical density of $>0.45$ was considered to be a positive result.

\section{DNA probes and colony hybridisation}

A recombinant plasmid, pAO111, containing the coding sequence for NAG-ST ${ }^{30}$ was used as the source of the DNA probe for the toxin. The digestion of pAO111 with restriction endonucleases, EcoRI and Bam HI released a 271-bp DNA fragment specific for the NAG-ST gene. $^{31}$ Similarly, EcoRI fragment (554 bp) of the plasmid, pKTN901 containing the A1 subunit of CT was used to screen all the $V$. cholerae non-O1 strains for the presence of a gene encoding CT. ${ }^{31}$ Furthermore, the distribution of the zot gene that encodes the zonula occludens toxin (ZOT), was examined with the ZOT DNA probe constructed by Karasawa et $a l .^{32}$ The procedure employed to purify the plasmid and to isolate and purify the DNA fragment has been described previously. ${ }^{21,31,32}$ Purified DNA was labelled with ${ }^{32} P$ by incorporating $[\alpha-$ $\left.{ }^{32} \mathrm{P}\right] \mathrm{dATP}$ to a specific activity of $2 \times 10^{8}$ $-8 \times 10^{8} \mathrm{cpm} / \mu \mathrm{g}$ of DNA by nick translation. Radiolabelled probe DNA was purified by chromatography on NACS PREPAC as specified by the manufacturer (Bethesda Research Laboratories, USA). The colony blot was prepared on autoclaved, gridded nitrocellulose filter (Schleicher and Schuell Co.; BA 85/20) and hybridisation was performed under high stringency as described previously. ${ }^{32}$

\section{Determination of cell-associated haemagglutinating activity}

Pooled group O human blood obtained from the Nil Ratan Sarkar Hospital blood bank, Calcutta, was stored at $4^{\circ} \mathrm{C}$ for not more than 1 week before use. When required for assay, blood cells were washed three times in $10 \mathrm{~mm}$ PBS (pH 7.4) and a $3 \%$ suspension was prepared. Bacterial suspensions from test strains grown on CFA (Colonisation Factor Antigen) agar (casamino acid, Difco, $1 \%$, yeast extract, Difco, $0.15 \%$, magnesium sulphate $0.005 \%$, manganese chloride $0.0005 \%$, Bacto agar $2 \%, \mathrm{pH} 7.4$ ) were made to yield $c .10^{9}$ cells $/ \mathrm{ml}^{33}$ To determine the cellassociated haemagglutinating activity, $20 \mu \mathrm{l}$ of bacterial suspension was mixed with the same volume of blood suspension on a glass slide at room temperature and rocked gently. Strains were recorded as $2+$ if the reaction was immediate and complete, or as $1+$ if the reaction was incomplete or not instantaneous but occurred within $5 \mathrm{~min}$. A PBS-blood cell control was always included.

\section{Inhibition of cell-associated haemagglutinating activity}

Strains that agglutinated erythrocytes were tested for haemagglutination inhibition by L-fucose, D-ga- 
Table I. Phenotypic characters of $V$. cholerae non-O1 isolates from hospitalised cases of acute diarrhoea

\begin{tabular}{lc}
\hline Characteric & $\begin{array}{c}\text { Percentage } \\
\text { positive } \\
(\mathrm{n}=28)\end{array}$ \\
\hline Oxidase & 100 \\
Ortho-nitro-phenyl-galactosidase & 100 \\
Arginine dihydrolase & 0 \\
Lysine decarboxylase & 100 \\
Ornithine decarboxylase & $96 \cdot 4$ \\
Simmons citrate & $32 \cdot 1$ \\
Hydrogen sulphide & 0 \\
Urease & 0 \\
Tryptophane deaminase & 0 \\
Indole & 100 \\
Acetoin production & $89 \cdot 3$ \\
Gelatin hydrolysis & 100 \\
Fermentation of: & \\
glucose & $96 \cdot 4$ \\
mannitol & 100 \\
inositol & 0 \\
sorbitol & 0 \\
rhamnose & 0 \\
sucrose & 100 \\
melibiose & $3 \cdot 6$ \\
amygdalin & $3 \cdot 6$ \\
arabinose & $3 \cdot 6$ \\
& \\
\hline &
\end{tabular}

Table II. Isolation status of $V$. cholerae non-O 1 in relation to serovar

\begin{tabular}{lccc}
\hline & \multicolumn{2}{c}{ Isolation status } & \\
\cline { 2 - 3 } Serovar & Sole isolate & Mixed infection & \\
\hline O5 & 5 & 4 & 9 \\
O7 & 1 & 0 & 1 \\
O8 & 0 & 1 & 1 \\
O11 & 2 & 2 & 4 \\
O14 & 1 & 0 & 1 \\
O26 & 0 & 1 & 1 \\
O34 & 4 & 0 & 4 \\
O39 & 1 & 0 & 1 \\
O97 & 1 & 0 & 1 \\
Untypable & 3 & 2 & 5 \\
Total & 18 & 10 & 28 \\
\hline
\end{tabular}

lactose or D-mannose. Bacterial suspensions were made in a $1 \% \mathrm{w} / \mathrm{v}$ solution of each sugar in PBS (pH 7.4). Haemagglutination was assessed by performing the test as described above. Inhibition was defined as $\geqslant 50 \%$ reduction in agglutination compared to that of the test without the sugar.

\section{Results}

During the 3-year period of the study (1989-1991), $V$. cholerae non-O1 was isolated from $28(4.7 \%)$ of the 591 patients hospitalised with acute diarrhoea. Of the 28 isolates (each strain representing a case), 18 were isolated as the sole infecting agent; the remaining 10 were isolated as co-cultures from cases infected with $V$. cholerae $\mathrm{O} 1$. The yearly isolation rate of $V$. cholerae non-O1 was $10 \%$ (5\% each as sole pathogen and in association with mixed infections) in 1989, 9.5\% (6.8\% as sole and $2.7 \%$ as mixed infections) in 1990 and $2.6 \%(1.9 \%$ as sole and $0.72 \%$ as mixed infections) in 1991. The phenotypic characteristics of the 28 isolates of $V$. cholerae non-O1 in this study are shown in table I. API profile numbers $5147124(57 \cdot 1 \%)$ and $5347124(25 \%)$ were predominant.

Of the 28 isolates of $V$. cholerae non-O1, $82 \%$ could be serotyped, with serovars O5 (32.1\%), O11 and O34 (14.3\% each) dominating (table II). Serovars O7, O14, O34, $\mathrm{O} 39$ and $\mathrm{O} 97$ were associated exclusively with sole infections. The culture supernates of two of the 28 strains of $V$. cholerae non-O1 (V254 and V315-1), both of which were untypable and were isolated as cocultures with $V$. cholerae $\mathrm{O} 1$, yielded a positive result in the CT bead-ELISA. The CT produced by both strains could be absorbed completely by anti-CT IgG. The same two strains that produced CT hybridised with the CT and ZOT DNA probes; the remaining 26 strains isolated in this study did not. None of the 28 strains of $V$. cholerae non-Ol hybridised with the NAG-ST DNA probe.

The effect of culture filtrates of the 28 strains on $\mathrm{CHO}, \mathrm{HeLa}$ and Vero cells is shown in table III. The majority of isolates produced a cytotoxic response in all the three cell lines, with end-point tires of 4-512. The cytotoxic response with disruption of the monolayer obtained with the $V$. cholerae non-O1 strains could be categorised into two types, one that was associated with complete membrane damage (figure, D) and the other was associated with cell rounding but without membrane damage (figure, E). Strains V59, V160 and V249 produced cytotoxic changes of the latter category in CHO cells; end-point titre of strain V59 was 512. In this category, no elongation of cells was observed just before the end-point titre. Fewer strains produced a cytotonic effect (figure, F); the end-point titres were 2-16. One of the two strains that produced CT (V315-1) showed a cytotonic effect on CHO and HeLa cells; in the other CT-producing strain (V254), the cytotonic effect appeared to be obliterated by a cytotoxic response on $\mathrm{CHO}$ and Vero cells without any changes being observed in HeLa cells. Apart from the two CT-producing isolates of $V$. cholerae non-O1, strain V157 showed a cytotonic response with HeLa cells and strains V160 and V249 showed cytotonic responses with HeLa and Vero cells, indicating the existence of cytotonic factors unrelated to CT.

None of the 28 strains produced a haemolysin that cross-reacted with the thermostable direct haemolysin of $V$. parahaemolyticus as determined by the beadELISA. However, $85.7 \%$ of the strains of $V$. cholerae non-O1 examined in this study haemolysed rabbit, sheep, chicken or human erythrocytes (table VI). Of the 28 strains of $V$. cholerae non-O1 examined, $75 \%$, $75 \%, 25 \%$ and $14.3 \%$ produced haemolysin that was 

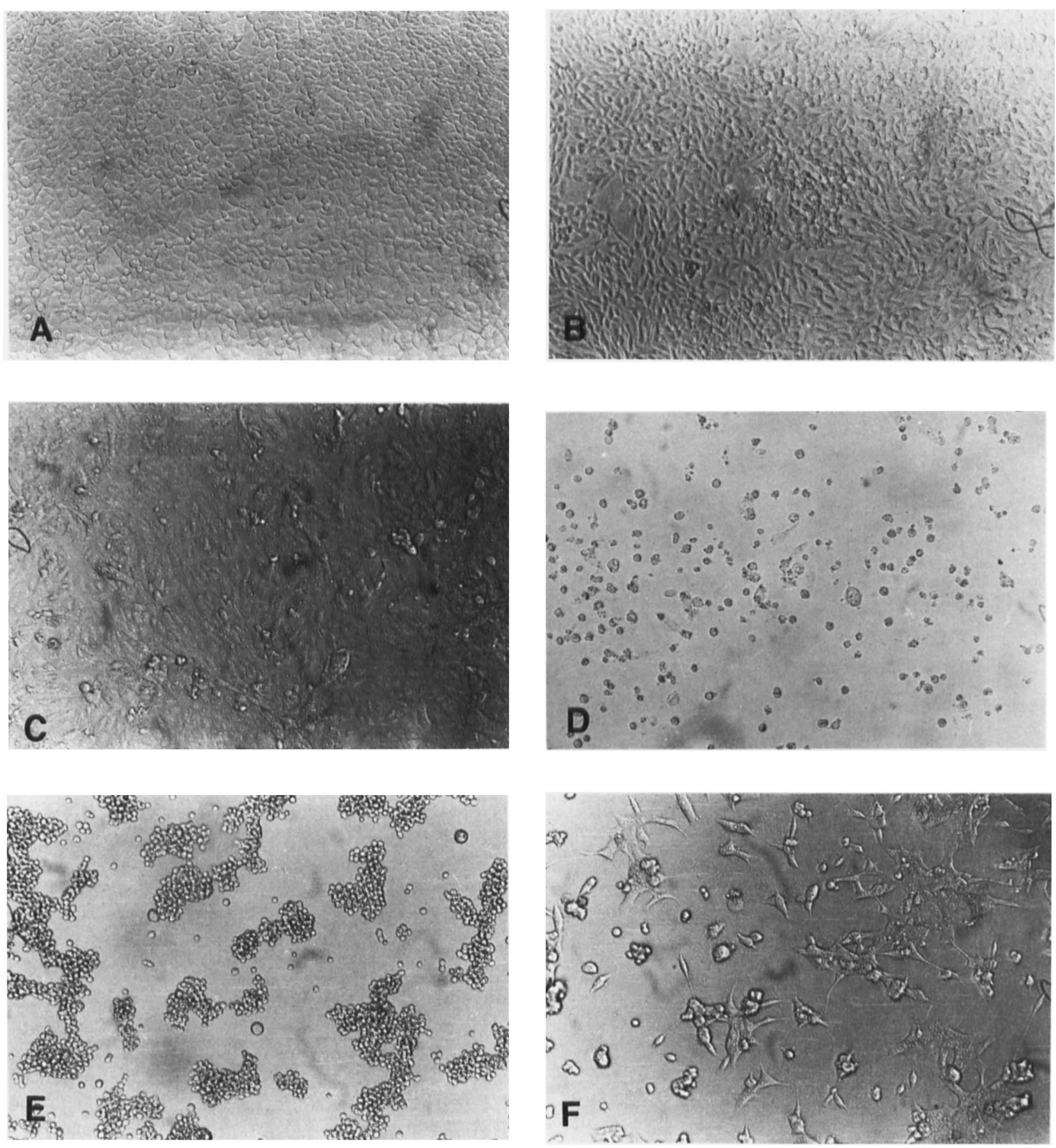

Figure 1. Effects of the culture filtrate of $V$. cholerae non-O1 strains isolated from clinical cases. Normal cells of HeLa (A), CHO (B) and Vero (C) cells with cytotoxic (D and $\mathbf{E}$ ) and cytotonic (F) effects on the respective cells.

Table III. Response of CHO, HeLa and Vero cells to culture filtrates of $V$. cholerae non-O1

\begin{tabular}{lcccc}
\multirow{2}{*}{$\begin{array}{l}\text { Morphological } \\
\text { change }\end{array}$} & Titre range & \multicolumn{3}{c}{ Number of strains positive in } \\
\cline { 3 - 5 } & & CHO cells & HeLa cells & Vero cells \\
\hline Unaffected & & 0 & 1 & 2 \\
Cytotoxic & $4-8$ & 5 & 10 & 7 \\
& $16-32$ & 14 & 7 & 7 \\
& $64-128$ & 4 & 6 & 9 \\
Cytotonic & $256-512$ & 3 & 0 & 1 \\
& $2-4$ & 1 & 2 & 0 \\
& $8-16$ & 1 & 2 & 2 \\
\hline
\end{tabular}

active against erythrocytes from rabbit, sheep (Eltor haemolysin), chicken and man, respectively. Strains that produced a haemolysin active against both rabbit and sheep erythrocytes were of the dominant type $(35 \cdot 7 \%)$. Two strains produced haemolysin(s) that was active against erythrocytes of rabbit, sheep, chicken and man (table IV). Ten $(35.7 \%$ ) of the 28 strains of $V$. cholerae non-Ol examined showed cellassociated haemagglutinating activity with human blood. Of the 10 strains, nine were isolated as sole pathogen and only one strain was associated with mixed infection (table V). Three distinct patterns of inhibition by sugars were detected; inhibition 
Table IV. Haemolytic activity of the strains of $V$. cholerae non-O1 with rabbit, sheep, chicken and human erythrocytes

\begin{tabular}{lc}
\hline Haemolytis of erythrocyte & Number of strains \\
\hline Rabbit, sheep, chicken, human & 2 \\
Rabbit, sheep, chicken & 5 \\
Rabbit, sheep, human & 1 \\
Rabbit, sheep & 10 \\
Rabbit, human & 1 \\
Rabbit & 2 \\
Sheep & 3 \\
None & 4 \\
Total & 28 \\
\hline
\end{tabular}

Table V. Patterns of inhibition of haemagglutination of $V$. cholerae non-O1 in relation to isolation status

\begin{tabular}{lccc}
\hline & \multicolumn{2}{c}{$\begin{array}{c}\text { Number of } \\
\text { Haemagglutination } \\
\text { inhibition pattern }\end{array}$} & \multicolumn{2}{c}{ Totrains positive } \\
\cline { 2 - 3 } & Sole isolate & Mixed infection & \\
\hline $\mathrm{M}^{+} \mathrm{F}^{-} \mathrm{G}^{+}$ & 5 & 1 & 6 \\
$\mathrm{M}^{+} \mathrm{F}^{+} \mathrm{G}^{-}$ & 2 & 0 & 2 \\
$\mathrm{M}^{+} \mathrm{F}^{+} \mathrm{G}^{+}$ & 2 & 0 & 2 \\
No haemagglutination $_{\text {Total }}$ & 9 & 9 & 18 \\
& 18 & 10 & 28 \\
\hline
\end{tabular}

*M, D-mannose ; F, L-fucose; G, D-galactose ; +, inhibition; - , no inhibition.

Table VI. Virulence phenotypes of the $V$. cholerae non-O1 isolates

\begin{tabular}{|c|c|c|c|}
\hline \multirow[b]{2}{*}{ Virulence phenotype* } & \multicolumn{2}{|c|}{ Number of strains } & \multirow[b]{2}{*}{ Total } \\
\hline & $\begin{array}{c}\text { Sole } \\
\text { isolate }\end{array}$ & $\begin{array}{c}\text { Mixed } \\
\text { infection }\end{array}$ & \\
\hline $\mathrm{Haem}^{+} \mathrm{Cyt}^{+} \mathrm{CT}^{-} \mathrm{Hagg}^{+} \mathrm{ZOT}^{-}$ & 7 & 1 & 8 \\
\hline $\mathrm{Haem}^{+} \mathrm{Cyt}^{+} \mathrm{CT}^{-} \mathrm{Hagg}^{-} \mathrm{ZOT}^{-}$ & 7 & 6 & 13 \\
\hline $\mathrm{Haem}^{-} \mathrm{Cyt}^{+} \mathrm{CT}^{-} \mathrm{Hagg}^{-} \mathrm{ZOT}^{-}$ & 2 & 1 & 3 \\
\hline $\mathrm{Haem}^{-} \mathrm{Cyt}^{+} \mathrm{CT}^{-} \mathrm{Hagg}^{+} \mathrm{ZOT}^{-}$ & 2 & 0 & 2 \\
\hline $\mathrm{Haem}^{-} \mathrm{Cyt}^{+} \mathrm{CT}^{+} \mathrm{Hagg}^{-} \mathrm{ZOT}^{+}$ & 0 & 1 & 1 \\
\hline $\mathrm{Haem}^{-} \mathrm{Cyt}^{-} \mathrm{CT}^{+} \mathrm{Hagg}^{-} \mathrm{ZOT}^{+}$ & 0 & 1 & 1 \\
\hline Total & 18 & 10 & 28 \\
\hline
\end{tabular}

* + , presence of the listed phenotype; - absence of the listed phenotype; Haem, ElTor haemolysin (active against sheep erythrocytes); Cyt, cytotoxin (CHO cells); CT, cholera toxin as determined by bead-ELISA; Hagg, haemagglutination (human Ogroup blood); ZOT, zonula occludens toxin determined by DNA probe.

of haemagglutination by mannose $1 \%$ but not by fucose and galactose $1 \%$ was the dominant haemagglutination inhibition pattern.

The composite virulence phenotypes of the 28 strains of $V$. cholerae non-Ol examined in this study are shown in table VI. A total of six different phenotypes was encountered. The prominent phenotype that was commonly associated with isolates from patients solely infected by $V$. cholerae non-O1 was exhibited by strains that produced the Eltor haemolysin, a hitherto unknown cytotoxin and a cellassociated haemagglutinin (table VI). The production of cell-associated haemagglutinin appeared to be the only distinctive phenotype that could distinguish between isolates from patients solely infected with $V$. cholerae non-O1 and those associated with mixed infections. Resistance of the 28 strains of $V$. cholerae non-O1 to antibiotics is shown in table VII. None of the isolates was resistant to tetracycline. The dominant antibiotic resistance pattern was ampicillin-streptomycin $(17.8 \%)$ followed by neomycin-streptomycin $(10 \cdot 7 \%)$.

\section{Discussion}

Apart from serological differences, it is virtually impossible to differentiate between $V$. cholerae strains belonging to the serovar $\mathrm{O} 1$ and those belonging to serovars other than $\mathrm{O} 1$, collectively termed as the non$\mathrm{Ol}$ group. However, these overtly similar organisms are very dissimilar in their pathogenic and epidemic potential, which has remained an enigma. Whereas CT is the major virulence factor in the pathogenesis of cholera, this study, like several others, ${ }^{34}$ has clearly demonstrated that $\mathrm{CT}$ production is an exception among strains of $V$. cholerae non-O1. More interestingly, however, was the concurrent incidence of the gene for ZOT, a newly described enterotoxin of $V$. cholerae ${ }^{35}$ with the ability of the $V$. cholerae nonO1 strains to produce CT. The $V$. cholerae non-O1 strains that did not produce CT did not carry the ZOT gene, as reported previously, ${ }^{32}$ which would indicate a possible synergic role for ZOT in the causation of the acute dehydrating diarrhoea mediated by CT-producing strains of $V$. cholerae. It has been suggested that ZOT may be responsible for the residual diarrhoea observed in human volunteers fed with recombinant strains of $V$. cholerae $\mathrm{O} 1$ attenuated by specific deletion of a major part of the gene encoding the A subunit of cholera toxin. ${ }^{35,36}$

The heat-stable enterotoxin (NAG-ST) was thought, at one time, to represent the principal virulence component of $V$. cholerae non-O1 but none of the isolates in this study hybridised with the NAGST gene probe. A recent study on the distribution of the NAG-ST gene among species of the genus Vibrio has shown conclusively that the incidence of the gene is very low among strains of $V$. cholerae non-O1. ${ }^{22}$ However, when present in association with suitable colonisation ability, the NAG-ST gene of $V$. cholerae non-O1 is a formidable factor that can cause diarrhoea of severity similar to that of cholera, as demonstrated recently by study in human volunteers. ${ }^{21}$

From this study, it appears that most strains of $V$. cholerae non-O1 produce a membrane-damaging cytotoxin. Only one previous study has shown the production of a Shiga-like toxin by $V$. cholerae nonO1. ${ }^{18}$ More than the Shiga-like toxin, the cytotoxic effect of $V$. cholerae non-O1 is probably related to the 
Table VII. Antibiotic resistance of 28 Vibrio cholerae non-O1 isolates

\begin{tabular}{lc}
\hline Antibiotic & $\begin{array}{c}\text { Resistant } \\
\text { isolates }(\%)\end{array}$ \\
\hline Ampicillin & $57 \cdot 1$ \\
Chloramphenicol & $7 \cdot 1$ \\
Co-trimoxazole & $10 \cdot 7$ \\
Furazolidone & $28 \cdot 6$ \\
Gentamicin & 25 \\
Nalidixic acid & 0 \\
Neomycin & $96 \cdot 4$ \\
Streptomycin & $46 \cdot 4$ \\
Tetracycline & 0 \\
\hline
\end{tabular}

production of various haemolysins considering the range of activity with erythrocytes of different types seen in this study. Most of the strains were haemolytic and $75 \%$ of them produced a haemolysin active against sheep erythrocytes, also known as the Eltor haemolysin. Purified Eltor haemolysin evokes fluid accumulation in the rabbit ileal loop, the infant rabbit and the suckling mouse models, suggesting that the Eltor haemolysin is an enterotoxic factor. ${ }^{16}$ The Eltor haemolysin of $V$. cholerae non-O1 is biologically, physicochemically and immunologically indistinguishable from the Eltor haemolysin elaborated by $V$. cholerae $\mathrm{O} 1$ belonging to the biotype Eltor. ${ }^{14,15}$ Evidence against the Eltor haemolysin as an important enterotoxic factor are the findings emerging from the Center for Vaccine Development, USA, which indicated that recombinant strains carrying the Eltor haemolysin gene (JBK70 and CVD101) or in which the Eltor gene has been deleted (CVD104 and CVD105) did not seem to influence the efficacy of the recombinant vaccine strains, indicating that the Eltor haemolysin does not play a role in the causation of diarrhoea. $^{36,37}$

When production of haemolysin or cytotoxin was analysed in conjunction with the haemagglutinating ability of the strain (a useful index of the attachment potential of pathogens), ${ }^{38}$ it appeared that strains of $V$. cholerae non-O1 that produced haemolysin, that were cytotoxic and that produced haemagglutinins were isolated most often as the sole pathogen. The cor- relation of the ability of a strain to produce cellassociated haemagglutinin and its incidence as the sole pathogen in this study was remarkable; of the 18 strains of $V$. cholerae non-O1 isolated as the sole enteropathogen, $50 \%$ produced cell-associated haemagglutinin, as compared with only one strain among the 10 recovered from mixed infections. $V$. cholerae $\mathrm{O} 1$ is known to produce several haemagglutinins whose importance in the adherence process in vivo has been suggested. ${ }^{19,20}$ The prominent haemagglutination-inhibition pattern exhibited by strains of $V$. cholerae non-O1 in this study was haemagglutination inhibited by mannose. Mannosesensitive haemagglutination has been described as the predominant cell-bound haemagglutinin in $V$. cholerae O1 Eltor biotype. ${ }^{20}$ However, the presence of haemagglutinins without an enterotoxic factor may not be significant, as $>62 \%$ of the environmental strains of $V$. cholerae non-O1 produce haemagglutinins or exohaemagglutinins $^{39}$ that are important for their survival in aquatic environments because they govern their ability to attach to different substrata. ${ }^{40}$

Considering the reported diversity of clinical symptoms elicited by $V$. cholerae non-O $1^{34}$ and considering its ubiquity in the environment, ${ }^{41}$ a single microbial determinant could not be expected to discriminate a pathogenic strain from a non-pathogenic one. Virulence in such organisms is multifactorial and mediated by several traits functioning in an integrated fashion, as clearly demonstrated by the human volunteer study in which a strain of $V$. cholerae non-O1 that produced NAG-ST but did not colonise or a strain that could colonise but did not produce NAGST did not cause diarrhoea; only a strain that possessed both the attributes precipitated diarrhoea. ${ }^{21}$ In conclusion, the clinical significance and virulence of $V$. cholerae non-O1 must be assessed in its totality and the presence of a single factor should not be construed as the cause of enteropathogenicity. It would be interesting in the future to trace the sequence of events which changes an innocuous isolate into an enteropathogenic one.

This work was partially supported by grants to G.B.N. (No. BT $/$ TF $/ 9 / 63 / 91$ ) from the Department of Biotechnology, New Delhi, India.

\section{References}

1. Morris JG, Wilson R, Davis BR et al. Non-O group 1 Vibrio cholerae gastroenteritis in the United States: Clinical, epidemiologic and laboratory characteristics of sporadic cases. Ann Intern Med 1981; 94: 656-658.

2. Gelbart SM, Prabhudesai MM. Vibrio cholerae non-O1 cellulitis. Arch Pathol Lab Med 1986; 110: 1182-1183.

3. Hughes JM, Hollis DG, Gangarosa EJ, Weaver RE. Noncholera Vibrio infections in the United States: clinical, epidemiologic, and laboratory features. Ann Intern Med 1978; 88: 602-606.

4. Safrin S, Morris JG, Adams M, Pons V, Jacobs R, Conte JE. Non-O1 Vibrio cholerae bacteremia: a case report and review. Rev Infect Dis 1988; 10: 1012-1017

5. Arita M, Takeda T, Honda T, Miwatani T. Purification and characterization of Vibrio cholerae non-O1 heat-stable enterotoxin. Infect Immun 1986; 52: 45-49.

6. Honda T, Arita M, Takeda T, Yoh M, Miwatani T. Non-O1 Vibrio cholerae produces two newly identified toxins related to Vibrio parahaemolyticus haemolysin and Escherichia coli heat-stable enterotoxin. Lancet 1985; 2 : 163-164.

7. Takao T, Shimonishi Y, Kobayashi M et al. Amino acid sequence of heat-stable enterotoxin produced by Vibrio cholerae non-O1. FEBS Lett 1985; 193: 250-254.

8. Yoshimura S, Takao T, Shimonishi Y et al. A heat-stable enterotoxin of Vibrio cholerae non-O1: chemical synthesis, and biological and physicochemical properties. Biopolymers 1986 ; 25: S69-S83.

9. Craig JP, Yamamoto K, Takeda Y, Miwatani T. Production of 
cholera-like enterotoxin by a Vibrio cholerae non-O1 strain isolated from the environment. Infect Immun 1981; 34: 90-97.

10. Yamamoto K, Takeda Y, Miwatani T, Craig JP. Stimulation by lincomycin production of cholera-like enterotoxin in Vibrio cholerae non-O1. FEMS Microbiol Lett 1981; 12: 245248.

11. Yamamoto K, Takeda Y, Miwatani T, Craig JP. Purification and some properties of a non-Ol Vibrio cholerae enterotoxin that is identical to cholera enterotoxin. Infect Immun 1983; 39: 1128-1135.

12. Yamamoto K, Takeda Y, Miwatani T, Craig JP. Evidence that a non-O1 Vibrio cholerae produces enterotoxin that is similar but not identical to cholera enterotoxin. Infect Immun $1983 ; 41: 896-901$.

13. Zinnaka Y, Carpenter CC. An enterotoxin produced by noncholera vibrios. Johns Hopkins Med J 1972; 13: 403-411.

14. Yamamoto K, Al-Omani M, Honda T, Takeda Y, Miwatani T. Non-O1 Vibrio cholerae hemolysin: purification, partial characterization, and immunological relatedness to $\mathrm{El}$ tor hemolysin. Infect Immun 1984; 45: 192-196.

15. Yamamoto $\mathrm{K}$, Ichinose $\mathrm{Y}$, Nakasone $\mathrm{N}$ et al. Identity of hemolysins produced by Vibrio cholerae, non-O1 and $V$. cholerae O1, biotype $\mathrm{El}$ tor. Infect Immun 1986; 51: 927-931.

16. Ichinose $\mathrm{Y}$, Yamamoto $\mathrm{K}$, Nakasone $\mathrm{N}$ et al. Enterotoxicity of El tor-like hemolysin of non-O1 Vibrio cholerae. Infect Immun 1987; 55: 1090-1093.

17. Yoh M, Honda T, Miwatani T. Production by non-O1 Vibrio cholerae of hemolysin related to thermostable direct hemolysin of Vibrio parahaemolyticus. FEMS Microbiol Lett 1985; 29: 197-200.

18. O'Brien AD, Chen ME, Holmes RK, Kaper J, Levine MM. Environmental and human isolates of Vibrio cholerae and Vibrio parahaemolyticus produce a Shigella dysenteriae 1 (Shiga)-like cytotoxin. Lancet 1984; 1: 77-78.

19. Datta-Roy K, Banerjee K, De SP, Ghose AC. Comparative study of expression of haemagglutinins, hemolysins, and enterotoxins by clinical and environmental isolates of nonO1 Vibrio cholerae in relation to their enteropathogenicity. Appl Environ Microbiol 1986; 52: 875-879.

20. Hanne LF, Finkelstein RA. Characterization and distribution of the haemagglutinins produced by Vibrio cholerae. Infect Immun 1982; 36: 209-214.

21. Morris JG, Takeda T, Tall BD et al. Experimental non-O group 1 Vibrio cholerae gastroenteritis in humans. $J$ Clin Invest $1990 ; 85: 697-705$.

22. Pal A, Ramamurthy T, Bhadra RK et al. Reassessment of the prevalence of heat-stable enterotoxin (NAG-ST) among environmental Vibrio cholerae non-O1 strains isolated from Calcutta, India, by using a NAG-ST DNA probe. Appl Environ Microbiol 1992; 58: 2485-2489.

23. World Health Organization. Programme for control of diarrhoeal diseases [CCD/83.3 Rev. 1]. In: Manual for laboratory investigations of acute enteric infections. Geneva, World Health Organization. 1987.

24. Nair GB, Misra S, Bhadra RK, Pal SC. Evaluation of the multitest medium for rapid presumptive identification of Vibrio cholerae from environmental sources. Appl Environ Microbiol 1987; 53: 1203-1205.
25. Shimada T, Sakazaki R, Kosako, Y. Occurrence and distribution of non-O1 Vibrio cholerae and its enterotoxigenicity (six years study). Kansenshogaku Zasshi 1982; 56: 1017-1024. (English abstract)

26. Oku Y, Uesaka Y, Hirayama T, Takeda Y. Development of a highly sensitive Bead-ELISA to detect bacterial protein toxins. Microbiol Immunol 1988; 32: 807-816.

27. Ramamurthy T, Bhattacharya SK, Uesaka Y et al. Evaluation of the bead enzyme-linked immunosorbent assay for detection of cholera toxin directly from stool samples. $J$ Clin Microbiol 1992; 30: 1783-1786.

28. Uesaka $Y$, Otsuka $Y$, Kashida $M$ et al. Detection of cholera toxin by a highly sensitive bead-enzyme linked immunosorbent assay. Microbiol Immunol 1992; 36: 43-53.

29. Nair GB, Oku Y, Takeda Y et al. Toxin profiles of Vibrio cholerae non-O1 from environmental sources in Calcutta, India. Appl Environ Microbiol 1988; 54: 3180-3182.

30. Ogawa A, Kato J-I, Watanabe H, Nair BG, Takeda T. Cloning and nucleotide sequence of a heat-stable enterotoxin gene from Vibrio cholerae non-O1 isolated from a patient with traveller's diarrhea. Infect Immun 1990; 58: 3325-3329.

31. Takeda T, Peina Y, Ogawa A et al. Detection of heat-stable enterotoxin in a cholera toxin gene-positive strain of Vibrio cholerae O1. FEMS Microbiol Lett 1991 ; 64: 23-27.

32. Karasawa T, Mihara T, Kurazono $\mathrm{H}$ et al. Distribution of the zot (zonula occludens toxin) gene among strains of Vibrio cholerae $\mathrm{O} 1$ and non-O1. FEMS Microbiol Lett 1993; 106: 143-146.

33. Evans DJ, Evans DG, Dupont HL. Haemagglutination pattern of enterotoxigenic and enteropathogenic Escherichia coli determined with human, bovine, chicken and guinea pig erythrocytes in the presence and absence of mannose. Infect Immun 1979; 23: 336-346.

34. Morris JG. Non-O group 1 Vibrio cholerae: A look at the epidemiology of an occasional pathogen. Epidemiol Rev $1990 ; 12: 179-191$.

35. Fasano A, Baudry B, Pumplin DW et al. Vibrio cholerae produces a second enterotoxin, which affects intestinal tight junctions. Proc Natl Acad Sci USA 1991; 88: 5242-5246.

36. Levine MM, Kaper JB, Herrington D et al. Volunteer studies of deletion mutants of Vibrio cholerae $\mathrm{O} 1$ prepared by recombinant techniques. Infect Immun 1988; 56: 161-167.

37. Levine MM, Kaper JB, Herrington D et al. Safety, immunogenicity, and efficacy of recombinant live oral cholera vaccines, CVD 103 and CVD 103-HgR. Lancet $1988 ; 2$ : 467-470.

38. Atkinson HM, Trust TJ. Hemagglutination properties and adherence ability of Aeromonas hydrophila. Infect Immun 1980; 27 : 938-946.

39. Dahlbäck B, Hermansson M, Kjellerberg S, Norkrans B. The hydrophobicity of bacteria - an important factor in their initial adhesion at the air-water interface. Arch Microbiol 1981 ; 128 : 267-270.

40. Amaro C, Toranzo AE, González EA et al. Surface and virulence properties of environmental Vibrio cholerae nonO1 from Albufera lake (Valencia, Spain). Appl Environ Microbiol 1990; 56: 1140-1147.

41. Nair GB, Sarkar BL, De SP, Chakrabarti MK, Bhadra RK, Pal $\mathrm{SC}$. Ecology of Vibrio cholerae in the fresh water environs of Calcutta, India. Microb Ecol 1988; 15: 203-215. 